\title{
PENGARUH PEMAKAIAN BAHAN BAKAR PREMIUM, PERTALITE DAN PERTAMAX TERHADAP KINERJA MOTOR 4 TAK
}

\author{
Maridjo, Ika Yuliyani, Angga R \\ Jurusan Teknik Konversi Energi, Politeknik Negeri Bandung \\ Email: mmaridjo1@gmail.com
}

\begin{abstract}
Abstrak
Penelitian ini bertujuan untuk membandingkan pengaruh bahan bakar premium, pertalite dan pertamax terhadap kinerja motor 4 tak. Seberapa besar pengaruh pemakaian berbagai bahan bakar terhadap kinerja mesin yang meliputi torsi, daya, putaran dan konsumsi bahan bakar. Dengan nilai oktan bahan bakar yang berbeda dan kompresi akan mempengaruhi besar torsi, daya juga konsumsi bahan bakar spesifik mesin. Mesin yang akan diuji yaitu motor 4 tak, merk Yamaha MX, 135 CC, manual. Pengujian menggunakan dynotest untuk mengetahui besarnya torsi dan daya mesin untuk berbagai variasi putaran dan uji statis dan jalan untuk menentukan konsumsi bahan bakar nya.

Hasil penelitian diperoleh torsi maksimum yang dihasilkan dari pengujian untuk bahan bakar premium 10,64 Nm pada putaran 5733 rpm; pertalite diperoleh torsi maksimum sebesar 10.37 Nm pada putaran mesin 5773 rpm, sedangkan pada bahan bakar pertamax turbo didapat tosi maksimum sebesar $11.09 \mathrm{Nm}$ pada putaran mesin 5636 rpm. Daya maksimum yang dihasilkan dari pengujian secara dynotest yaitu pada bahan bakar premium 10,1 HP pada putaran 8056 rpm; pertalite didapat daya maksimum sebesar $10 \mathrm{HP}$ pada putaran mesin $8166 \mathrm{rpm}$; sedangkan pada bahan bakar pertamax turbo didapat daya maksimum sebesar 10.3 HP pada putaran mesin 8158 rpm. Konsumsi bahan bakar yang dihasilkan dari pengujian jalan oleh bahan bakar premium 21,79ml/km; pertalite didapat nilai konsumsi bahan bakar sebesar $28.85 \mathrm{ml} / \mathrm{km}$ sedangkan bahan bakar pertamax turbo didapat nilai konsumsi bahan bakar sebesar $23.08 \mathrm{ml} / \mathrm{km}$. Pemakaian bahan bakar premium untuk Yamaha MX 135 dibanding bahan bakar lain, torsi dan daya yang dihasilkan tidak terlalu beda nilainya, tetapi konsumsi bahan bakarnya cukup berbeda.
\end{abstract}

Kata kunci : premium, pertalite, pertamax turbo, performansi, 4 tak

\section{PENDAHULUAN}

Di Indonesia, tersedia berbagai bahan bakar mesin bensin 4 tak yang memiliki spesifikasi yang berbeda beda, seperti premium, pertalite dan pertamax. Spesifikasi yang sangat membedakan diantara bahan bakar tersebut yaitu nilai oktannya. Harga berbagai bahan bakar tersebut juga bervariasi. Harga bahan bakar terendah Rp.6500/liter untuk premium dan $\mathrm{Rp}$ 9400/liter untuk pertamax. Pertalite merupakan BBM non subsidi merupakan produk baru 
Pertamina dengan nilai oktana diantara premium dan pertamax. Kebanyakan masyarakat awam saat ini membeli bahan bakar untuk kendaraannya hanya berdasar harga per liter yang paling murah, mengingat semua bahan bakar dapat digunakan di kendaraannya. Masyarakat menganggap semua bahan bakar sama. Masyarakat belum mengkaji sejauh apa pengaruh bahan bakar yang digunakan terhadap performa kendaraannya. Untuk itu pada penelitian ini, dikaji pengaruh bahan bakar premium, pertalite dan pertamax terhadap performa /kinerja kendaraan 4 tak yang meliputi torsi, daya , putaran dan konsumsi bahan bakar spesifiknya.

\section{TINJAUAN PUSTAKA}

Beberapa kajian tentang pengaruh bahan bakar terhadap kinerja mesin sudah dilakukan oleh peneliti .

Eri Sururi dan Budi Waluyo (2012) meneliti perbandingan bahan bakar premium dan pertamax terhadap performa motor Suzuki thunder. Hasil penelitian menunjukkan bahwa torsi terbaik dihasilkan bahan bakar premium yaitu 10,21 kgf.m pada putaran $6000 \mathrm{rpm}$. Daya terbaik untuk premium dan pertamax sama yaitu 10,85 HP pada putaran $10000 \mathrm{rpm}$. Konsumsi bahan bakar spesifik pada 5000-8000 rpm premium lebih baik daripada pertamax, tetapi $9000 \mathrm{rpm}$ keatas pertamax lebih baik.[1]

Tri Bagus Purnomo (2013) meneliti perbandingan bahan bakar premium dan pertamax terhadap performa motor Yamaha mio $110 \mathrm{cc}$, Hasil penelitian menunjukkan bahwa torsi tertinggi dihasilkan bahan bakar pertamax yaitu sebesar $186 \mathrm{Nm}$ pada putaran $1750 \mathrm{rpm}$, daya tertinggi juga dihasilkan oleh pertamax yaitu sebesar 3,5 $\mathrm{kW}$ pada putaran $2000 \mathrm{rpm}$. [2]

\section{Motor Otto}

Motor Otto atau motor bensin pertama kali ditemukan pada tahun 1876. Motor bensin yang ditemukan oleh Otto menggunakan siklus empat langkah. Setiap empat kali langkah piston menghasilkan satu kali kerja atau tenaga.
Sehingga motor empat langkah seringkali disebut dengan sebutan motor Otto.

Motor Otto adalah jenis mesin pembakaran dalam yang menggunakan nyala busi untuk proses pembakaran, dirancang untuk menggunakan bahan bakar gasoline atau yang sejenis. Mesin bensin berbeda dengan mesin diesel dalam metode pencampuran bahan bakar dengan udara. Mesin bensin selalu menggunakan penyalaan busi untuk proses pembakaran. Pada mesin diesel, hanya udara yang dikompresikan dalam ruang bakar dan dengan sendirinya udara menjadi panas, kemudian bahan bakar diinjeksikan ke dalam ruang bakar di akhir langkah kompresi maka campuran udara dan bakar tersebut akan terbakar dengan sendirinya.

Siklus Otto (ideal) pembakaran tersebut dimisalkan dengan pemasukan panas pada volume konstan. [6]

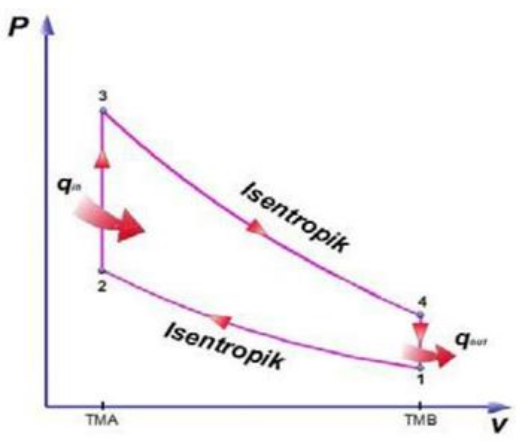

Gambar1. Diagram P-v Siklus Otto

Keterangan Gambar :

$\mathrm{P}=$ Tekanan $(\mathrm{atm})$

$\mathrm{V}=$ Volume Spesifik $(\mathrm{m} / \mathrm{kg})$

qout $=$ Kalor yang dibuang $(\mathrm{kJ})$

Pada Motor Otto, udara dan bahan bakar dicampur lebih dahulu sebelum masuk ke ruang bakar, sebagian kecil mesin motor bensin modern mengaplikasikan injeksi bahan bakar langsung ke silinder ruang bakar termasuk mesin bensin 4 langkah untuk mendapatkan emisi gas buang yang ramah lingkungan. Percampuran udara dan bahan bakar dilakukan oleh karburator atau sistem injeksi. Sistem injeksi bahan bakar dimotor 
bensin terjadi diluar silinder, tujuannya untuk mencampur udara dengan bahan bakar seproposional mungkin, hal ini disebut EFI (Electronic Fuel Injection ).

\section{Bahan Bakar}

Bahan bakar adalah bahan/material apapun yang bisa diubah menjadi energi. Bahan bakar mengandung energi panas yang dapat dilepaskan jika di oksidasikan atau dibakar. [5]

Beberapa jenis bahan bakar :

a. Bahan Bakar Padat

Bahan bakar padat berupa padatan, Contohnya kayu , batubara dansebagainya. Daya panas yang dihasilkan dapat dipakai untuk memanaskan air menjadi uap untuk menggerakkan peralatan serta menyediakan energi.

b. Bahan Bakar Cair

Bahan bakar bersifat cair yaitu bahan bakar yang strukturnya tak rapat, bila dibandingkan dengan bahan bakar padat. Molekulnya bisa bergerak bebas. Bensin atau gasoline, minyak tanah, dan solar merupakan salah satu contoh bahan bakar yang berbentuk cair. Bahan bakar cair umum digunakan dalam industri, industry transportasi ataupun rumah tangga. Bahan bakar cair yang nanti akan diuji yaitu premium, pertalite, pertamax.

c. Bahan Bakar Gas

Bahan bakar gas jenisnya macam macam. Berikut ini adalah contoh dari beberapa bahan bakar gas yaitu :

- Gas Alam

- Propana

- Butana

- Bahan bakar memegang peranan penting dalam motor bakar, nilai kalor yang terkandung didalamnya adalah nilai yang menyatakan jumlah energi panas maksimum yang dibebaskan oleh suatu bahan bakar melalui reaksi pembakaran sempurna persatuan massa atau volume bahan bakar tersebut.
Saat ini banyak sekali masalah yang timbul diakibatkan oleh cadangan bahan bakar minyak yang terbatas dan harganya yang semakin melambung.

\section{Bahan bakar bensin/premium}

Bensin atau petrolium adalah cairan campuran yang berasal dari minyak bumi dan sebagian besar tersusun dari hidrokarbon serta digunakan dalam mesin pembakaran dalam sebagai bahan bakar. . Angka oktan adalah angka yang menunjukan berapa besar tekanan maksimum yang bisa diberikan didalam mesin sebelum bahan bakar terbakar secara spontan. Angka oktan adalah suatu nilai yang menunjukkan sifat anti ketukan (detonasi). Dengan arti kata lain, makin tinggi angka oktan maka dapat mengurangi terjadinya detonasi (knocking).

\section{Bahan Bakar Pertalite}

Pertalite adalah bahan bakar minyak dari pertamina dengan RON 90. Pertalite

dihasilkan dengan penambahan zat aditif dalam proses pengolahannya di kilang minyak. pertalite memiliki beberapa keunggulan dibandingkan dengan premium. Selain itu, RON 90 membuat pembakaran pada mesin kendaraan dengan teknologi terkini lebih baik dibandingkan dengan premium yang memiliki RON 88. Sehingga sesuai digunakan untuk kendaraan roda dua, hingga kendaraan multi purpose vehicle ukuran menengah.

\section{Pertamax}

Bahan bakar pertamax mempunyai nilai oktan lebih tinggi disbanding pertalite. [7]

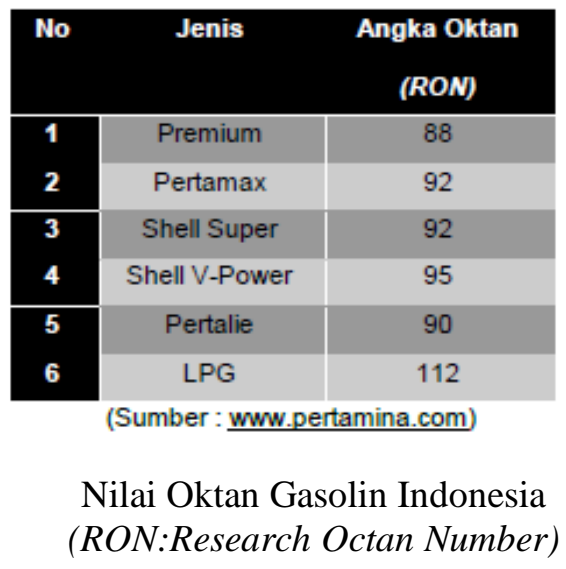


(Sumber : www.pertamina.com

\section{Spesifikasi Yupiter MX, 135 CC. [8]}

Spesifikasi unit uji yang digunakan sebagai berikut,

- Tipe Mesin

Empat Katup

: Empat Langkah, DOHC -

- Kapasitas Mesin

: $135 \mathrm{cc}$

- Sistem Pendingin Mesin: Liquid Cooled

- Diameter x Langkah

: $57.3 \times 57.8$

- Perbandingan Kompresi : 10,9 : 1

\section{Performansi / kinerja motor}

Parameter kinerja motor ini adalah torsi, daya, konsumsi bahan bakar spesifik dan efesiensi dari pembakaran didalam mesin. [6]

\section{a. Daya dan torsi}

Daya merupakan salah satu parameter dalam menentukan peforma motor. Perbandingan perhitunagan daya terhadap berbagai macam motor tergantung pada putaran mesin dan momen putar/torsi itu sendiri. Semakin cepat putaran mesin, rpm yang dihasilkan semakin besar sehingga daya yang dihasilkan juga semakin besar, begitu juga momen putar motornya, akan mempengaruhi daya yang dihasilkan. Dengan demikian jumlah putaran (rpm) dan besarnya momen putar atau torsi mempengaruhi daya motor yang dihasilkan oleh sebuah motor

$\mathrm{W}=\mathrm{T} .2$ л $\mathrm{n} / 60000$

Dimana :

$\mathrm{W}=$ Daya $(\mathrm{kW})$

$\mathrm{n}=$ Putaran Mesin (rpm)

$\mathrm{T}=$ Torsi $(\mathrm{Nm})$

\section{b. Torsi}

Torsi adalah ukuran kemampuan mesin untuk melakukan kerja. Torsi dapat diperoleh dari hasil kali antara gaya dengan jarak :

$\mathrm{T}=\mathrm{F} \times \mathrm{s}(\mathrm{N} \cdot \mathrm{m})$

Dimana :

$\mathrm{T}=$ torsi $(\mathrm{Nm})$

$\mathrm{F}=$ gaya sentrifugal $(\mathrm{N})$ $\mathrm{s}=\operatorname{jarak}(\mathrm{m})$

\section{c. Konsumsi bahan bakar spesifik (SFC)}

Perhitungan konsumsi bahan bakar spesifik ini digunakan untuk mengetahui jumlah bahan bakar yang dibutuhkan untuk mnempuh jarak satu km, bisa juga didefinisikan jumlah bahan bakar yang dibutuhkan untuk menghasilkan daya dalam waktu tertentu.

$\mathrm{SFC}=\mathrm{V} / \mathrm{s}(\mathrm{l} / \mathrm{km})$

SFC $=$ spesifik fuel consumtion (Konsumsi bahan bakar spesifik) $1 / \mathrm{km}$

$\mathrm{V}=$ Volume bahan bakar yang terpakai

$\mathrm{S}$ = jarak yang ditempuh

\section{Tahapan penelitian}

Tahapan penelitian yang dilakukan sebagai berikut :

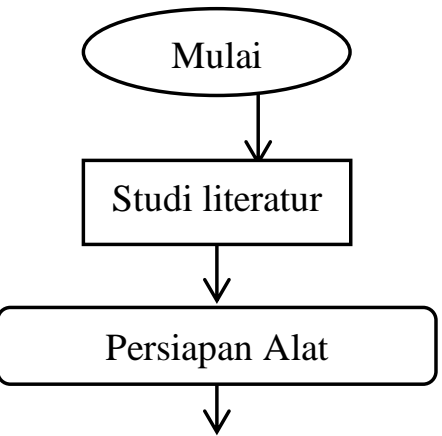

Pengujian Torsi, Daya, dan Konsumsi Bahan Bakar premium, pertalite dan Pertamax

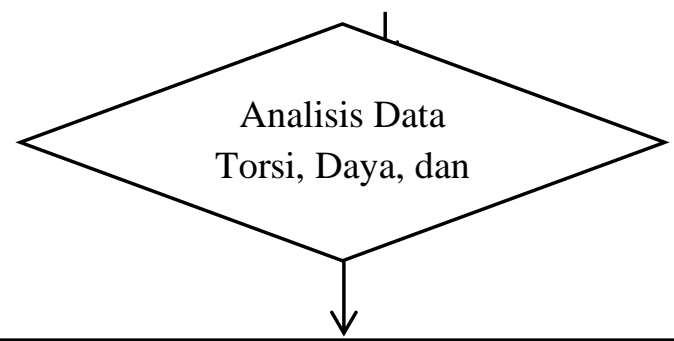

Perbandingan pengaruh premium, pertalite dan pertamax terhadap performansi engine 4 tak

Penyusunan Laporan Penelitian 


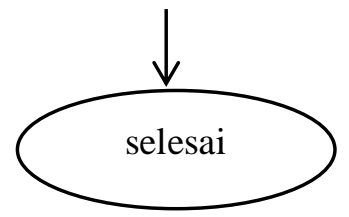

HASIL DAN PEMBAHASAN

Perubahan torsi terhadap perubahan putaran mesin dapat dilihat pada gambar dibawah ini :

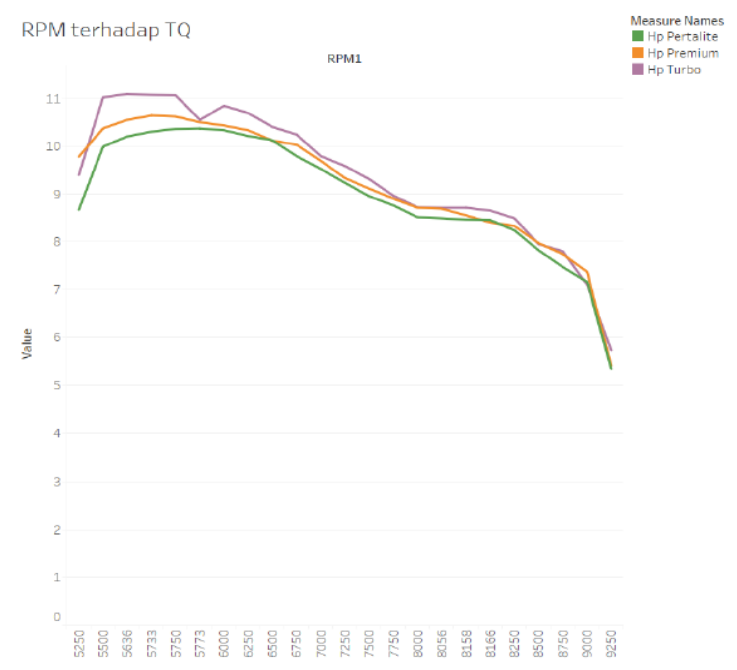

Gambar 2. Perubahan torsi terhadap putaran

Torsi tertinggi pada bahan bakar premium dan pertalite dicapai pada putaran yang sama. Perbedaan nilai torsi yang dihasilkan bahan

bakar premium dan pertalite tidak terlalu besar, nilainya sekitar $0,27 \mathrm{Nm}$. Dari grafik dapat dilihat bahwa nilai torsi untuk bahan bakar premium untuk semua putaran hasilnya lebih besar meskipun perbedaannya sangat kecil. Dengan selisih nilai oktan yang hanya dua tidak terlalu berpengaruh terhadap torsi yang dihasilkan. Untuk pertamax turbo, nilai torsi ada diatas torsi menggunakan premium dan pertalite, perbedaan torsi tertinggi sekitar $0,7 \mathrm{Nm}$. pada bahan bakar pertamax turbo daya yang dihasilkan yaitu sebesar $10.3 \mathrm{Hp}$ pada putaran mesin $8158 \mathrm{rpm}$.

Perubahan daya terhadap perubahan putaran mesin dapat dilihat pada gambar dibawah ini

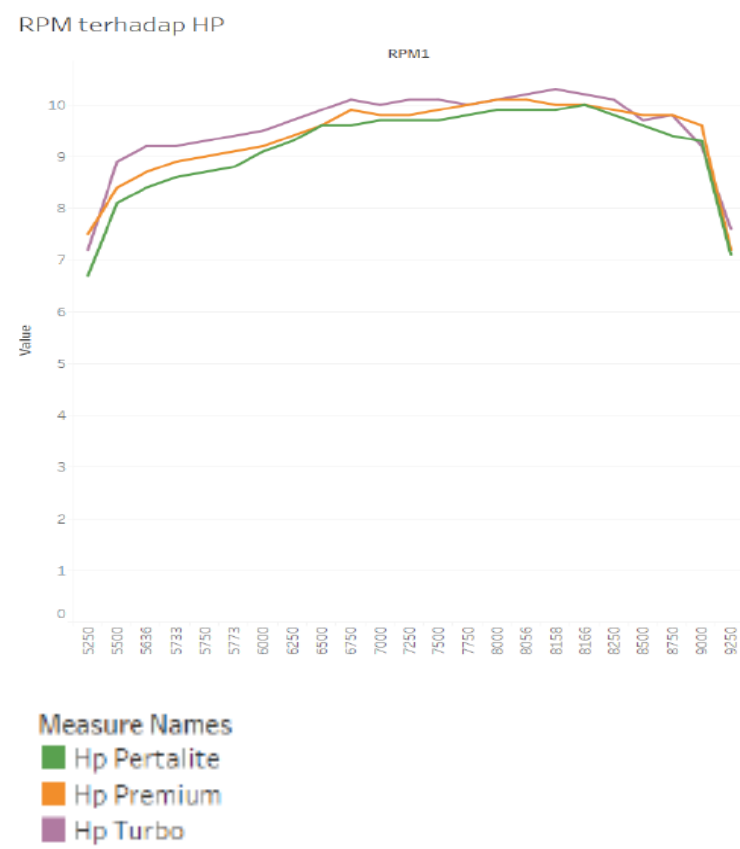

Gambar 3. Perubahan daya terhadap putaran

Selanjutanya pada gambar 3 dapat dilihat bahwa daya yang dihasilkan oleh bahan bakar premium yaitu sebesar 10,1 HP pada putaran $8066 \mathrm{rpm}$; untuk pertalite yaitu sebesar $10 \mathrm{Hp}$ pada putaran mesin 8166rpm; sedangkan pada bahan bakar

Pada pengujian konsumsi bahan bakar dapat dilihat baha terdapat perbedaan dari penggunaan bahan bakar premium, pertalite dan pertamax turbo. Pemakaian rata rata bahan bakar 
premium sebesar $21,79 \mathrm{ml}$ per $\mathrm{km}$; untuk pertalite $28,85 \mathrm{ml}$ per $\mathrm{km}$ dan pertamax turbo 23,08 $\mathrm{ml}$ per $\mathrm{km}$. Pemakaian premium lebih irit dibanding bahan bakar lain.

\section{KESIMPULAN}

\section{Kesimpulan}

Dari hasil pengujian analisis pengaruh bahan bakar premium, pertalite dan pertamax turbo pada sepeda motor yamaha jupiter $\mathrm{mx}$ $135 \mathrm{cc}$, dapat disimpulkan :

1. Torsi maksimum yang dihasilkan dari pengujian secara dynotest yaitu pada bahan bakar premium 10,64 Nm pada putaran 5733 rpm; pertalite diperoleh torsi maksimum sebesar $10.37 \mathrm{Nm}$ pada putaran mesin $5773 \mathrm{rpm}$, sedangkan pada bahan bakar pertamax turbo didapat tosi maksimum sebesar $11.09 \mathrm{Nm}$ pada putaran mesin $5636 \mathrm{rpm}$.

2. Daya maksimum yang dihasilkan dari pengujian secara dynotest yaitu pada bahan bakar premium 10,1 HP pada putaran $8056 \mathrm{rpm}$; pertalite didapat daya maksimum sebesar 10 HP pada putaran mesin $8166 \mathrm{rpm}$; sedangkan pada bahan bakar pertamax turbo didapat daya maksimum sebesar 10.3 HP pada putaran mesin $8158 \mathrm{rpm}$.

3. Konsumsi bahan bakar yang dihasilkan dari pengujian jalan oleh bahan bakar premium $21,79 \mathrm{ml} / \mathrm{km}$; pertalite didapat nilai konsumsi bahan bakar sebesar 28.85 $\mathrm{ml} / \mathrm{km}$ sedangkan bahan bakar pertamax turbo didapat nilai konsumsi bahan bakar sebesar $23.08 \mathrm{ml} / \mathrm{km}$.

4. Penggunaan bahan bakar pada sepeda motor harus merujuk kembali pada buku manual dari sepeda motor dimana pada motor jupiter mx $135 \mathrm{cc}$ dengan rasio kompresi $10.9: 1$ disarankan menggunakan bahan bakar dengan nilai oktan tidak terlalu tinggi yaitu cukup premium..

\section{DAFTAR PUSTAKA}

[1] Sururi E., \& waluyo, B. (2012). Kaji Eksperimental perbandingan penggunaan premium dan pertamax terhadap unjuk kerja mesin pada sepeda motor Suzuki Thunder tipe EN-125. Teknik mesin. Universitas Muhammadiyah Magelang. Magelang

[2] Purnomo, T. B. (2013). Perbedaan performa motor berbahan bakar premium 88 dan motor berbahan bakar pertamax 92 . Teknik mesin. Universitas negeri Semarang. Semarang.

[3] Rapotan Saragih dan Djoko Sungkono Kawano, (2013) Pengaruh Penggunaan Bahan Bakar Premium,Pertamax, Pertamax Plus Dan Spiritus Terhadap Unjuk Kerja Engine Genset 4 Langkah, JURNAL TEKNIK POMITS Vol. 2, No. 1, (2013) ISSN: 2337-3539

[4] P. Nara dkk,(2017), Pengaruh perbandingan penggunaan bahan bakar minyak pertalite dan bahan bakar gas LPG terhadap unjuk kerja motor Honda Supra Fit, Jurnal Jurusan Pendidikan Teknik Mesin (JJPTM) Ganesha Volume : Vol : 8 No : 2 Tahun 2017

[6] Wiranto Aris Munandar, edisi 2015, Motor bakar, penerbit ITB

[7] PT. Pertamina Indonesia. 2015. Pengertian dan Keunggulan Bahan Bakar Pertalite. Jakarta Indonesia.

[8] PT. Yamaha Indonesia. 2015. Spesifikasi Motor Yamaha MX 135 